\title{
The Differentiated Pricing Strategy or Hotel under Dual-Channel Reservation Forms
}

\author{
Xiaoyan Xu, Rui Zhao*, Liang Xu \\ School of Management, University of Science and Technology of China, Hefei, China \\ Email: ${ }^{2}$ hr11@mail.ustc.edu.cn
}

Received 6 March 2014; revised 7 April 2014; accepted 15 April 2014

Copyright (C) 2014 by authors and Scientific Research Publishing Inc.

This work is licensed under the Creative Commons Attribution International License (CC BY). http://creativecommons.org/licenses/by/4.0/

(c) (i) Open Access

\begin{abstract}
The modern information network environment largely changed consumer habits. Hotel Reservation way becomes increasingly diversified. By building the traditional and Internet booking ways' demand functions which were linear in self- and cross-price effects and the hotel revenue function, we determine the optimal pricing strategy of the hotel's Internet booking way. The effect of the optimal strategy is also discussed, and numerical simulation verifies that the optimal strategy can greatly improve the hotel revenue. All of the research propositions help hotel managers make deeper understanding of fixed room quantity's influence on pricing strategies, and provide managers the basis of pricing strategy.
\end{abstract}

\section{Keywords}

Differentiated Pricing Strategy; Multi-Channel Reservation; Hotel Revenue Management

\section{Introduction}

The rise of the Internet are profoundly changing the consumer's lifestyle and spending habits. According to the survey of a well-known online booking platform in China, more than 1 million customers book hotel rooms through their platform every year and more than $40 \%$ of them book hotel rooms through the online booking way. iResearch statistics show that in 2013 China's online travel market transactions amounted to 220.46 billion Yuan, an increase of $29.0 \%$ [1]. Online travel growth depends mainly on the growth of online hotel and business. But to grab market share, frequent promotional activities led the hotel commission income declined.

The article [2] pointed out that adding a direct online channel has a number of advantages, such as increasing control over pricing and product selection, and enabling the manufacturer to reach a wider segment of customers and to engage in price discrimination. Of course, adding an online channel also has a number of potential disad-

*Corresponding author. 
vantages, including the competition in channels, which may lead to lower prices and potentially reduced profits for both channels (Gretzel, U., Yoo, K. H. [3]). Hotel online booking way is an indispensable channel of hotel rooms selling (Ashton, A. S. [4]; O’Connor, P. and Frew, A. J., [5]), so the hospitality industry is no longer just adopt price war, but determine the pricing strategy of online booking rooms scientifically.

For hotel, the price of guest rooms is an important factor of hotel revenue. Customers often get some discount by using online booking way; the price will have certain differences with traditional reservation method. Therefore, the hotels tend to provide rooms for traditional channels to get more profit. This paper will mainly analysis how to determine the optimal way of online booking discount prices for hotel in order to get maximum benefit under multi-channel reservation environment.

In terms of theory, the earliest to introduce the Revenue management into hotel service industry is Sieburgh [6]. He considered the hotel revenue management as a kind of profit maximization strategy which is concerned with the market sensitive pricing of fixed room capacity relative to specific market characteristics. Years of hotel revenue management research focus on how to make full use of fixed room capacity, using the best price reasonably allocated rooms to market segmentation, maximize profit (Kimes, S. E. [7]; Jones, P. [8]; Chen, X. [9]; Liu Shu-Qin, Wang Shou-Yang [10]; Badinelli, R. D. [11]; Chen Wu-Hua, Sun Yan-Hong, Hua ZhongSheng [12]). The traditional hotel revenue management study takes the pricing as a result of the supply and demands joint action in different periods. But along with the formation of modern information network environment that appears online booking habits, hotel booking online emerged. Taking into account the impact of the online booking form, reservation demand of various forms will not only determined by their own price, but also by the other order price.

The introduction of the online channel in a tangible product supply chain management, as well as theoretical results of competition and cooperation between the two channels have been very mature (Ryan, J. K., Sun, D., Zhao, X. [2]; Xu Lei, Li Yong-Jian [13]; Xiao Jian, Dan Bin, Zhang Xu-Mei [14]). In terms of dual channels that compete on price, Jennifer K. Ryan [2] studied the demand substitution and price competition between traditional channel and online channel, found that in cases where the traditional channel has a larger market than the online channel, the manufacturer could increase overall revenue by selling the products in different channels at different prices. In China, Xu Lei and Li Yong-Jian [13] analyzed the optimal decision of four dual channel structures, efficiency of different structures, as well as the impact of network channel entry on incumbent enterprises and supply chain efficiency. Xiao Jian et al. [14] studied the service cooperation pricing strategy between manufacturers and retailers in dual channel supply chain. But for the hospitality industry, its service capacity is limited by the number of rooms; these studies did not take service capacity into consideration, so the theoretical results of tangible product dual-channel supply chain cannot be directly used to guide the pricing of hotel. We study the impact of the number of rooms in multi-channel reservations, where the substitution effect between multiple booking ways caused by price differences and the service capacity limited are both considered, and gives accurate model solutions.

In this paper, considering the reality situation in the hospitality industry facing network environment, we model the traditional and online booking ways' demand functions which were linear in self- and cross-price effects as well as the hotel revenue function, we determine the optimal pricing strategy for the hotel's online booking way. By using econometric methods, we identified the optimal pricing strategy of online booking way and analysis the efficiency of multiple booking ways. This paper is organized as follows: Section 2 introduces the notation and hypothesis. In Sections 3, we formulate the decision models for the hotel manager, analyze the hotel rooms' influence to Dual-channel reservations. In Section 4, we report the results of numerical experiments carried out to investigate the factors that influence pricing strategies. We conclude the results and suggest topics for future research in Section 5.

\section{Hypothesis}

Consider the follow hotel room sales model: a hotel provides two kinds of reservation ways, one is traditional reservation method $X$ and the other is online reservation method $Y$, the hotel rooms is $N$. The traditional reservation's price is stable and not infrequent change, but the online reservation's price is lower than traditional method keeping in a flexible way. Now we assume the $X$ method's price is $p$, the $Y$ method's price is $p \cdot d$ (In order to make the study clearly, we take $p=1$ ). Thinking about the room sold by traditional reservation method provide more revenue, based on the hotel rooms, it should be retained to meet the consumer demand for $X$ me- 
thod firstly and then provides the rooms for $Y$ method. The switch cost between the two kind reservations is low enough and it makes the consumer to transfer one reservation method to the other reservation method easily. For the hotel, it should make an optimal pricing in $Y$ method to enhance the hotel's revenue management considering the room numbers and the potential customer demand.

Based on the information above, we provide three hypotheses:

H1: the $X$ method's price is established and it is $p$. (We assume $p=1$ here).

$\mathrm{H} 2$ : The two method demand function is substitutes for each other with the price.

H3: Thinking about the hotel's capacity, it provides the room for $X$ reservation method firstly and then meet the demand of $Y$ reservation method.

\section{Model and Results}

\subsection{The Model}

Since our goal is to investigate the impact of online booking way in a competitive market environment, our demand model must adequately reflect the substitutability of the two methods. Thus, we adopt a typical linear demand substitution model. Following (Hua, G., Wang, S., \& Cheng, T. E. [15]), we assume that the demand functions are linear in self- and cross-price effects, but with different parameters for each method, i.e., the demand functions are formulated as follows:

$$
\begin{gathered}
D_{X}=a_{1}-b_{1} p+c_{1} d p \\
D_{Y}=a_{2}-b_{2} d p+c_{2} p
\end{gathered}
$$

The parameters $b_{i}$ and $c_{i}, i \in\{1,2\}$, represent the own-price and cross-price sensitivities of demand. Generally, one would expect the $X$ demand to be more sensitive to the $X$ method's price than to the $Y$ method's price. Similarly, the $Y$ demand would be more sensitive to the $Y$ method's price than to the $X$ method's price. This would imply $b_{1}>c_{1}, b_{2}>c_{2}$. Also, $a_{1}$ represents the base market size purchasing through method $X ; a_{2}$ represents the base market size purchasing through method $Y$. The parameter $c_{i}$ captures the substitutability between the two methods, i.e., higher values of $c_{i}$ imply that the channels are viewed as closer substitutes. Thus, $b_{i}$ and $c_{i}$ will depend on the customers' preferences regarding booking online versus in a traditional way.

Hence, the total demand is

$$
D=D_{X}+D_{Y}=\left(a_{1}+a_{2}\right)-\left(b_{1}-c_{2}\right)-\left(b_{2}-c_{1}\right) d
$$

Since the total demand of the two methods should be downward sloping in the $X$ 's price and $Y$ 's price, we have $b_{1}>c_{2}, b_{2}>c_{1}$.

The hotel daily revenue comes from two parts: one part come from method $X$, determined by $\pi_{X}=\min \left\{N, D_{X}\right\}$, hotel allocated enough rooms meet the demand for $X$, that is this part of rooms bring sales revenue at the original price; the other part is created by method $Y$, determined by $\pi_{Y}=d \min \left\{\left(N-D_{X}\right)^{+}, D_{Y}\right\}$, hotel provide the remaining amount of the hotel rooms to method $Y$ at discount $d$. Then, the total profit of the hotel is

$$
\pi(d)=\min \left\{N, D_{X}\right\}+d \min \left\{\left(N-D_{X}\right)^{+}, D_{Y}\right\}
$$

Due to the price of $Y$ is not higher than the way of $X$, hotel revenue maximization model for the optimal pricing strategies is:

$\max \pi(d)$

s.t. $\quad 0 \leq d \leq 1$

Mark this model for M1.

\subsection{Optimal Pricing Strategy}

Model M1 is a piecewise continuous function, based on (1) - (4), this section we will analyze the optimal price $d^{*}$ and hotel revenue in the limit of the number of rooms $N$.

Proposition 1. When $N \leq a_{1}-b_{1}$, method $Y$ should not be used, the hotel revenue is given by $\pi=N$. 
Proposition 2. When $a_{1}-b_{1}<N \leq a_{1}-b_{1}+c_{1}$, we get the optimalprice $d^{*} \in\left[\frac{N-a_{1}+b_{1}}{c_{1}}, 1\right]$.

That is $\min \left\{N, D_{X}\right\}=N, \min \left\{\left(N-D_{X}\right)^{+}, D_{Y}\right\}=0$, The hotel did not allocate rooms to the way consumers book online, hotel revenue is given by $\pi=N$.

Proposition 3. When $a_{1}-b_{1}+c_{1}<N \leq a_{1}-b_{1}+c_{1}+a_{2}-b_{2}+c_{2}$, we get the optimal price $d^{*}=1$.

Thus, $\min \left\{N, D_{X}\right\}=a_{1}-b_{1}+c_{1}, \min \left\{\left(N-D_{X}\right)^{+}, D_{Y}\right\}=N-a_{1}+b_{1}-c_{1}$, Consumer demand of online

booking habits is very exuberant, the hotel have enough consumers check-in at full price, hotel revenue is given by $\pi=N$.

\section{Proposition 4.}

1) When $a_{1}-b_{1}+c_{1}+a_{2}-b_{2}+c_{2}<N<a_{1}-b_{1}+a_{2}+c_{2}$ and $a_{2}-b_{2}+c_{2} \geq b_{2}-c_{1}, d^{*}=1$.

2) When $a_{1}-b_{1}+c_{1}+a_{2}-b_{2}+c_{2}<N<a_{2}+c_{2}+a_{1}-b_{1}-\frac{\left(b_{2}-c_{1}\right)\left(a_{2}+c_{1}+c_{2}\right)}{2 b_{2}}$ and $a_{2}-b_{2}+c_{2}<b_{2}-c_{1}$, $d^{*}=\frac{a_{2}+c_{2}+a_{1}-b_{1}-N}{b_{2}-c_{1}}$.

3) When $a_{2}+c_{2}+a_{1}-b_{1}-\frac{\left(b_{2}-c_{1}\right)\left(a_{2}+c_{1}+c_{2}\right)}{2 b_{2}}<N<a_{1}-b_{1}+a_{2}+c_{2}$ and $a_{2}-b_{2}+c_{2}<b_{2}-c_{1}$, $d^{*}=\frac{a_{2}+c_{1}+c_{2}}{2 b_{2}}$.

\section{Proposition 5.}

1) When $a_{1}-b_{1}+a_{2}+c_{2}<N$ and $a_{2}-b_{2}+c_{2} \geq b_{2}-c_{1}, d^{*}=1$.

2) When $a_{1}-b_{1}+a_{2}+c_{2}<N$ and $a_{2}-b_{2}+c_{2}<b_{2}-c_{1}, d^{*}=\frac{a_{2}+c_{1}+c_{2}}{2 b_{2}}$.

\subsection{The Effect of the Optimal Pricing Strategy}

We mark the expected revenue under no online booking method with $\pi^{0}$, the expected revenue under optimal pricing strategy with $\pi\left(d^{*}\right)$. We use $\Delta \pi=\pi\left(d^{*}\right)-\pi^{0}$ to describe the effect of optimal pricing strategy. Then, we will analysis the effect of the optimal pricing strategy with different hotel rooms by using the way of online booking.

Under the situation of proposition 1, the traditional reservation demand exceeds the rooms hotel can offer, so there is no need to adopt the way of booking online.

Under the situation of proposition 2, the supply quantity of rooms under traditional reservation method is given by $S_{X}=a_{1}-b_{1}+c_{1} \times d^{*}=N$, the supply quantity of rooms under online reservation method is given by $S_{Y}=0$, and the increase revenue is $\Delta \pi=N-a_{1}+b_{1}$. In this case, the hotel did not allocate rooms to online reservations method, hotel use online reservations to attract consumers who have online booking habits; thus we obtain the lower bound of online reservations price, so that consumers would not abandon the traditional reservations because of the spread of the two reservations' price is too large. And in the case of Proposition 2, the lower bound of this price increase with the increase in the number of rooms.

Under the situation of proposition 3 , the supply quantity of rooms under traditional reservation method is given by $S_{X}=a_{1}-b_{1}+c_{1} \times d^{*}=a_{1}-b_{1}+c_{1}$, the supply quantity of rooms under online reservation method is given by $S_{Y}=N-a_{1}+b_{1}-c_{1}$, and the increase revenue is $\Delta \pi=N-a_{1}+b_{1}$. In this case, hotel cannot satisfy the consumer demand of all $Y$ way, hotel distribution part of the rooms to $Y$ way at full price.

Under the situation of proposition $4 a$, the supply quantity of rooms under traditional reservation is given by $S_{X}=a_{1}-b_{1}+c_{1}$, the supply quantity of rooms under online reservation is given by $S_{Y}=a_{2}-b_{2}+c_{2}$ and the increase revenue is $\Delta \pi=c_{1}+a_{2}-b_{2}+c_{2}$. In this situation, the hotel can totally meet the customer demands of both $X$ and $Y$ method. Starting from the consumer features, the ratio between the least demands of online reservation method and the abandon demands due to the high price in total demands has an important impact on the optimal pricing while adding the online reservation method. When the ratio is bigger than 1 , in other words, the 
consumers' price sensitivity is low enough, the two kind of reservation methods has the same pricing strategy and it has no influence on the room number.

Under the situation of proposition $4 \mathrm{~b}$, the supply quantity of rooms under traditional reservation is given by $S_{X}=a_{1}-b_{1}+c_{1}\left(\frac{a_{2}+c_{2}+a_{1}-b_{1}-N}{b_{2}-c_{2}}\right)$, the supply quantity of rooms under online reservation is given by $S_{Y}=N-S_{X}$ and the increase revenue is $\Delta \pi=N-a_{1}+b_{1}$. In this situation, the hotel room number has an impact on optimal pricing and the more rooms, the lower price. In the room number range of proposition $4 \mathrm{~b}$, the hotel cannot totally meet the customers' demand of online reservation method. But with the hotel room number increase, the price of online reservation should be decreasing.

Under the situation of proposition $4 \mathrm{c}$, the supply quantity of rooms under traditional reservation is given by $S_{X}=a_{1}-b_{1}+c_{1}\left(\frac{a_{2}+c_{1}+c_{2}}{2 b_{2}}\right)$, the supply quantity of rooms under online reservation is given by $S_{Y}=\frac{a_{2}-c_{1}+c_{2}}{2}$ and the increase revenue is $\Delta \pi=\frac{\left(a_{2}+c_{1}+c_{2}\right)^{2}}{4 b_{2}}$. In this situation, the potential demands of online reservation method, the cross price sensitive factor and the self-sensitive of online reservation all play the decisive role on optimal pricing. It shows that the pricing strategy is based on the customers' feature. The more potential customers, the higher price; the bigger cross price sensitive factor, the higher price; the self-sensitive factor of online reservation is higher, the price is lower.

Under the situation of proposition $5 \mathrm{a}$, the supply quantity of rooms under traditional reservation is given by $S_{X}=a_{1}-b_{1}+c_{1} d^{*}=a_{1}-b_{1}+c_{1}$, the supply quantity of rooms under online reservation method is given by $S_{Y}=a_{2}-b_{2}+c_{2}$, and the increase revenue is $\Delta \pi=c_{1}+a_{2}-b_{2}+c_{2}$. This situation is consistent with the proposition 4a.

Under the situation of proposition $5 \mathrm{~b}$, the supply quantity of rooms under traditional reservation is given by $S_{X}=a_{1}-b_{1}+c_{1}\left(\frac{a_{2}+c_{1}+c_{2}}{2 b_{2}}\right)$, the supply quantity of rooms under online reservation method is given by $S_{Y}=\frac{a_{2}-c_{1}+c_{2}}{2}$, and the increase revenue is $\Delta \pi=\frac{\left(a_{2}+c_{1}+c_{2}\right)^{2}}{4 b_{2}}$. This situation is consistent with the proposition 4c.

\section{Numerical Analysis}

Based on the completion of building the hotel traditional reservation methods' and online reservation methods' demand functions and revenue functions, combining with the results of the model solution, we are going to specific analysis how the hotel room number and consumer characteristics infect the hotel revenue. In this paper, we use the calculation software mat lab 7.1 to finish the research.

1) Hotel room number's influence on hotel revenue

At this part, we assume the traditional reservation method's demand function is $D_{X}=100-20+8 d$, the online reservation method's demand function is $D_{Y}=50-40 d+8$, the other variables have been identified, the hotel room number ranges from 75 to 115 . The results show below in Table 1.

We can find out from Table 1, with the hotel room number increasing, the optimal discount decrease in a monotonically way, the allocation using by $\mathrm{Y}$ style and hotel revenue and its growth are all increasing. Till the online reservation room number stabilize to the hotel guest room capacity, the hotel revenue and its growth both don't increase any more, the optimal discount stables in a certain level.

2) Consumer characteristics' influence on hotel revenue and optimal pricing

At this part, we assume $\theta=\frac{a_{2}-b_{2}+c_{2}}{b_{2}-c_{1}}$, it represent a ratio that the minimum demand in online reservation compare to abandon purchase number in total demand because of the high price in online reservation method. When $\theta$ it is bigger than 1, it means that the online reservation method consumers have a low sensitivity. When it isn't, means that they have a high sensitivity. The figure below show how $\theta$ impacts on the hotel 
revenue and optimal pricing.

We can find out from Figure 1, with the hotel room numbers increase the optimal pricing is not decreasing in a monotonically way. In situation 2, the online reservation price is lower than traditional method. In situation 1 , 2, 3, consumer characteristics have no influence on the optimal pricing. Hotel revenue becomes more and more with the hotel room number increasing till a certain number. At this time, both traditional reservation and online reservation are meted. In satiation 4 and 5, when $\theta \leq 1$, the online reservation price is lower than traditional reservation. Only in situation 4 , optimal pricing is inversely proportional to the hotel room number. When the hotel room number meet in situation 5 , hotel room number have no influence on optimal pricing. When $\theta \geq 1$ both traditional reservation and online reservation offer the same price, and the hotel revenue is bigger than when $\theta \leq 1$.

\section{Conclusions}

During the progressive development and profound changing among the consumers' spending patterns and habits causing by the Internet, the hotel reservation has changed from traditional offline to online and offline combination form and it makes the consumers obtaining greater consumer surplus possibly. For the hotel service providers, how to balance the traditional way and online way, especially the pricing strategy about them, becomes the most important research issue in hotel reservation management.

Based on the previous studies, the hotel reservation is divided into traditional way and online way, the researcher build two kinds of linear alternative demand functions and hotel revenue functions, at last they calculate the hotel optimal discount rate $\mathrm{d}$ and discuss how the different factors influencing the hotel revenue. The results shows: facing the traditional method and online method, hotel reservation revenue management becomes more complex and systematic. The price is not linearly decreasing with the number of rooms increasing and

\begin{tabular}{cccccccccccccccc}
\multicolumn{1}{l}{ Table 1. Hotel room number's influence on hotel revenue. } \\
\hline Hotel room number & 75 & 80 & 83 & 86 & 89 & 96 & 105 & 107 & 109 & 111 & 113 & 115 \\
Optimal discount & - & - & 1 & 0.76 & 1 & 1 & 1 & 0.97 & 0.91 & 0.84 & 0.82 & 0.82 \\
Y method's rooms allocation & - & - & 0 & 0 & 1 & 8 & 17 & 19 & 21 & 24 & 25 & 25 \\
Hotel revenue & 75 & 80 & 83 & 86 & 89 & 96 & 105 & 106 & 107 & 107 & 107 & 107 \\
Revenue growth & - & - & 3 & 6 & 9 & 16 & 25 & 26 & 27 & 27 & 27 & 27 \\
\hline
\end{tabular}
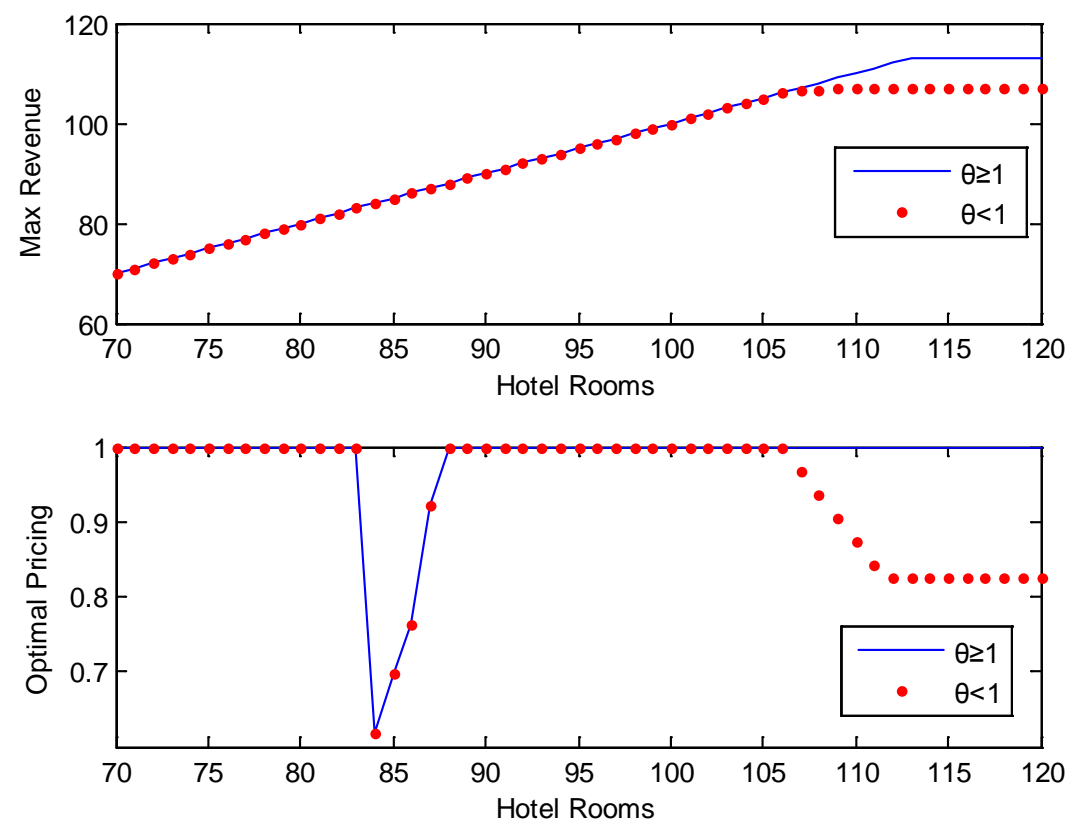

Figure 1. Consumer characteristics' influence on hotel revenue and optimal pricing. 
under the different size of hotel, the price strategy is different. In this paper, we give an optimal pricing strategy under the different hotel size.

In this paper, we make a deeply research in hotel revenue management under different reservation methods and in the model we simply boils down the difference in reservation methods into price difference in reservation method. For different reservation methods, the difference is not only in price but also in service quality, timing limit and so on, it provides a new starting point in further research.

\section{References}

[1] Zhang, X.-L. (2013) Chinese E-Commerce Development Report in the Third Quarter of 2013. http://news.iresearch.cn/zt/225528.shtml

[2] Ryan, J.K., Sun, D. and Zhao, X. (2013) Coordinating a Supply Chain with a Manufacturer-Owned Online Channel: A Dual Channel Model under Price Competition. IEEE Transactions on Engineering Management, 60, 247-259.

[3] Gretzel, U. and Yoo, K.H. (2008) Use and Impact of Online Travel Reviews. Information and Communication Technologies in Tourism 2008, Springer Vienna, 35-46. http://dx.doi.org/10.1007/978-3-211-77280-5_4

[4] Ashton, A.S. (2014) Tourist Destination Brand Image Development-An Analysis Based on Stakeholders’ Perception: A Case Study from Southland, New Zealand. Journal of Vacation Marketing. http://dx.doi.org/10.1177/1356766713518061

[5] O’Connor, P. and Frew, A.J. (2004) An Evaluation Methodology for Hotel Electronic Channels of Distribution. International Journal of Hospitality Management, 23, 179-199. http://dx.doi.org/10.1016/j.ijhm.2003.10.002

[6] Sieburgh, J.A. (1988) Yield Management at Work at Royal Sonesta. Lodging Hospitality, 44, 235-237.

[7] Kimes, S.E. (1989) The Basics of Yield Management. The Cornell Hotel and Restaurant Administration Quarterly, 30, 14-19. http://dx.doi.org/10.1177/001088048903000309

[8] Jones, P. (1999) Yield Management in UK Hotels: A Systems Analysis. Journal of the Operational Research Society, 1111-1119.

[9] Xu, C. (2003) Hotel Revenue Management: Research Overview and Prospects. Journal of Management Sciences in China, 6, 72-78.

[10] Liu, S.-Q. and Wang, S.-Y. (2010) Hotel Room Pricing Strategy with the Scheduled Time Limit. Mathematics in Practice and Theory, 2010, 36-41.

[11] Badinelli, R.D. (2000) An Optimal, Dynamic Policy for Hotel Yield Management. European Journal of Operational Research, 121, 476-503. http://dx.doi.org/10.1016/S0377-2217(99)00046-6

[12] Chen, W.-H., Sun, Y.-H. and Hua, Z.-S. (2013) Joint Pricing of Multiple Types of Rooms in Hotel under Customer Choice. Journal of Management Sciences in China, 16, 23-33.

[13] Xu, L. and Li, Y.-J. (2013) On Supply Chain Mixed Channel Problem Considering Consumer Behavior. Systems Engineering-Theory \& Practice, 33, 1672-1681.

[14] Xiao, J., Dan, B. and Zhang, X.-M. (2010) Service Cooperation Pricing Strategy between Manufacturers and Retailers in Dual-Channel Supply Chain. Systems Engineering-Theory \& Practice, 2010, 2203-2211.

[15] Hua, G., Wang, S. and Cheng, T.E. (2010) Price and Lead Time Decisions in Dual-Channel Supply Chains. European Journal of Operational Research, 205, 113-126. http://dx.doi.org/10.1016/j.ejor.2009.12.012 